\title{
Therapy of Respiratory Complications in Myasthenia Gravis
}

\author{
PAUL SALAHORU1', CRISTINA MIHAELA GHICIUC2*, CRISTINA GRIGORESCU², MARIUS VALERIU HINGANU³, \\ ALEXANDRU PATRASCU ${ }^{4}$, CATALINA ELENA LUPUSORU² \\ ${ }^{1}$ Grigore T. Popa University of Medicine and Pharmacy, Faculty of Medicine, Thoracic Surgery Department, 16 Universitatii Str., \\ 700115, Iasi, Romania \\ ${ }^{2}$ Grigore T. Popa University of Medicine and Pharmacy, Faculty of Medicine, Pharmacology Department, 16 Universitatii Str., \\ 700115, lasi, Romania \\ ${ }^{3}$ Grigore T. Popa University of Medicine and Pharmacy, Faculty of Medicine, Anatomy Department, 16 Universitatii Str., 700115, \\ lasi, Romania \\ ${ }^{4}$ Hospital Sf Dimitrie, Orthopedic - Traumatology Compartment, 35 Stefan cel Mare Blvd., 615200, Tirgu Neamt, Romania
}

\begin{abstract}
Myasthenia gravis is responsible for damaging the neurosurgical structures in charge of producing and supporting the breathing process. Plasmapheresis is the procedure that non selectively removes the potentially pathological elements from the blood.It is done extracorporeally, and has multiple clinical applications, especially in situations when intensive care is required. In patients with moderate or severe forms, or with no favourable therapeutic response to cholinesterase inhibitors, corticosteroids and / or immunosuppressive therapy are administered.
\end{abstract}

Keyords: Myasthenia gravis, Plasmapheresis, Respiratory manifestations

Respiratory manifestations of myasthenia gravis occur when the disease is responsible for damaging the neurosurgical structures in charge of producing and supporting the breathing process [1,2].

Patients suffering from myasthenia gravis, with presence of anti acetylcholinereceptor antibodies (AchRAb) show a marked improvement in the level of circulating specific antibodies, usually immediately after the first plasmapheresis treatment, commonly administered in the emergency setting [3,4].

Plasmapheresis is the procedure that non selectively removes the potentially pathological elements from the blood $[5,6]$. It is done extracorporeally, and has multiple clinical applications, especially in situations when intensive care is required $[7,8]$.

Drug therapy consists of administration of cholinesterase inhibitors (non-steroidal antigens), of which Piridostigmine is the first-choice of treatment $[9,10]$. In some cases, Neostigmine can be administered [9,11]. In patients with moderate or severe forms, or with no favourable therapeutic response to cholinesterase inhibitors, corticosteroids and / or immunosuppressive therapy are administered [12,13].

\section{Experimental part}

Materials and methods

In order to analyze the respiratory manifestations in patients suffering of myastenia gravis undergoing an acute myasthenic crisis episode, we evaluated 2 female patients that had participated in a retrospective study.
The two patients were initially part of a retrospective study of 14 patients, were the following aspects had been evaluated : the dynamics of AchR-Ab levels and the clinical picture in patients with a myasthenia gravis diagnosis who had benefited from thymectomy.

The patients were admitted to the Department of Thoracic Surgery of the Hospital of Pneumophysiology in lasi, between 2014 and 2017.

Patients who presented with myasthenic events, with an AchR-ab level of less than $1 \mathrm{nmol} / \mathrm{L}$ or who had no surgical indication for a thymic disorder were excluded from the retrospective study.

Each of these patients was evaluated preoperatively and 6 months postoperatively (thymectomy) on clinical symptomatology and AchR levels. Remission was considered to be a clinical manifestation, defined as absence of symptoms for a minimum of 3 months.

The information gathered from the patient evaluation was entered into the database. The results were obtained using descriptive statistics.

The patient evaluation started with assessing the inclusion and exclusion criteria presented.

These criteria are detailed in table 1.

After assessment of the inclusion criteria and the exclusion criteria for the present study for each patient, we established the criteria for the database design, for which Microsoft Office Excel 2007 was used.

We introduced in the latter database relevant information on anamnesis, clinical examination, common paraclinical examinations, specific paraclinical

\begin{tabular}{|l|l|}
\hline Criteria for inclusion in the study & Criteria for exclusion from the study \\
\hline $\begin{array}{l}\text { Existence of diagnosis of myasthenia gravis, } \\
\text { confirmed by specific techniques }\end{array}$ & The existence of mental illness \\
\hline an AChR-ab titre value of at least $1 \mathrm{nmol} / \mathrm{L}$ & $\begin{array}{l}\text { Patients with surgery that can influence } \\
\text { sphimatology and specific drug therapy }\end{array}$ \\
\hline $\begin{array}{l}\text { The presence of a CT scan that is } \\
\text { objectively diagnosed }\end{array}$ & Patients with chronic infections \\
\hline & Patients with epilepsy \\
\hline & $\begin{array}{l}\text { Patients undergoing drug therapy with: } \\
\text { aminoglycosides, curating agents, } \\
\text { magnesium salts, quinidine or } \\
\text { antiepileptics }\end{array}$ \\
\hline
\end{tabular}

Table 1

CRITERIA TO INCLUDE IN STUDY / EXCLUSION FROM THE STUDY IMPLEMENTED

*email: c_ghiciuc@yahoo.com; cpislariu@gmail.com; 
assessment, Computer Tomogaph imaging, diagnostics (primary/ secondary), associated thymic conditions, type of surgery, histo-pathological diagnosis and specific elements related to clinical development.

This database was subsequently supplemented with information obtained from the postoperative assessment at 6 months.

All the documented information in the database was evaluated using descriptive statistics.

As such, all patients enrolled in the study received an evaluation sheet, which included the following main parameters:

1. Anamnesis:

- Symptoms,

- Heredo-collateral medical history (with particular reference to pathology of the thymus), personal physiological history (with reference, especially for women, to developing cardiac symptoms in relation to hormone fluctuation and menopause), personal pathological history, work, behaviour (smoking, ethanol consumption, etc.), medication administered prior to admission, and disease history.

2. General clinical examination and a review of systems, insisting on muscle competence and presence / absence of palpebral ptosis.

3. Complete cardiovascular examination:

- Blood pressure and heart rate,

- Electrocardiogram, Doppler ultrasound,

- Exercise stress test.

4. Thyroid function evaluation,

5. Clinical symptoms during hospitalization,

6. Laboratory determinations: PT).

-Hematological parameters (CBC, Hb, Ht, Gr, Tr, INR /

-Biochemical parameters (blood glucose, total cholesterol, HDL, LDL, triglycerides, uric acid).

-Inflammatory parameters (WBC, CRP, ESR, fibrinogen).

-Specific laboratory tests for myasthenia gravis: -cholinesterase inhibitors test; -circulating antibodiestitration (ELISA / RIPA);

7. Imaging examination: thoracic radiography, computer tomography,

8. Myographic study.

All of these elements were analyzed, with a particular interest in observing the influence of the thymic affection on the clinical picture and on the antibody dynamics in patients with myasthenia gravis.

Following the study, two cases of hospitalized patients presenting respiratory manifestations during the acute myasthenic crisis were selected.

The two cases benefited from further assessment, highlighting the particularities determined by specific myasthenic crisis symptoms, as well as additional specific investigations and therapy.

The present paper represents a detailed discussion on the two selected cases.

\section{Results and discussions}

The two patients were hospitalized and treated in the emergency with symptoms specific to acute myasthenic crisis.

Both patients were females, aged 23 and 28 years old, with middle-class urban backgrounds.

Both patients denied ethanol consumption and smoking.

Also, the anamnesis revealed secondary manifestations specific to myasthenia gravis:

-Patient 1 presented with palpebral ptosis associated with axial muscle weakness, limb weakness, and respiratory manifestations of acute myasthenic crisis;
Patient 2 presented pal pitations, diplopia, limb and axial musclew eakness, and respiratorymanifestations of acute myasthenic crisis.

For each patient,the primary diagnosis of myasthenia gravis was associated with a series of secondary diagnoses presented in table 2.

Table 2

SECONDARY DIAGNOSIS FOR EACH OF THESE 2 EVALUATED PATIENTS

\begin{tabular}{|l|l|}
\hline PATIENT 1 & PATIENT 2 \\
\hline Palpebral ptosis & palpebral ptosis \\
\hline Acute respiratory failure & Acute respiratory failure \\
\hline Secondary anemia & Secondary anemia \\
\hline & Bilateral diplopy \\
\hline
\end{tabular}

Both patients received paraclinical assessment and imaging to detect possible associated thymic disorder. Type A thymoma was found in both cases.

Both patients had thus indication for thymectomy and both underwent the procedure. Ab.

Laboratory tests included measurements of the AchR-

Preoperative, the patients were found to have high specific antibody concentrations as follows: $123 \mathrm{nmol} / \mathrm{L}$ (patient 1), $148 \mathrm{nmol} / \mathrm{L}$ (patient 2). Given the high titre of AChR-ab, plasmapheresis was indicatedin both cases.

The two patients both received 2 preoperative plasmapheresis sessions, followed postoperatively by 3 sessions for the patient 1 and 4 for the patient 2 , respectively. The circulating antibodieslevels was measured at regular intervals prior to each session of plasmapheresis, and their evolution is presented in figure 1 .

\section{PATIENT 1}

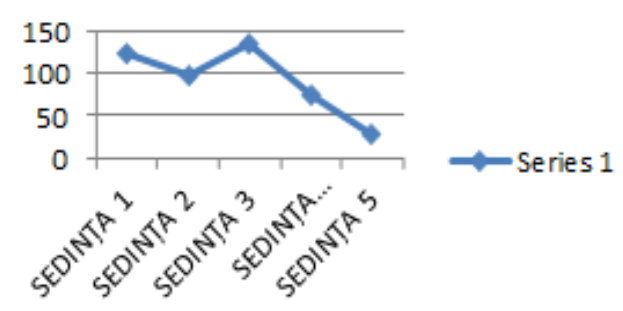

\section{PATIENT 2}

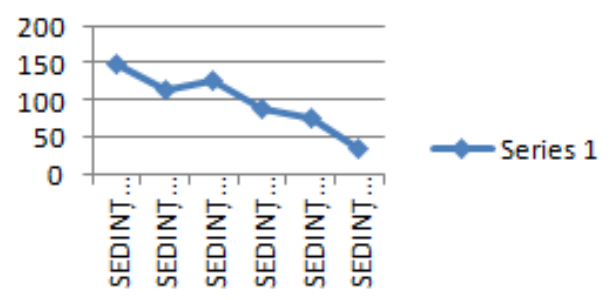

Fig.1. Dynamics of ACHR-AB antibodies, measurements before your Plasmafereze Mettings. Meetings 1,2 have been realized for the preparator

From the analysis of the two tables showing the dynamics of AChR-ab levels, measured in $\mathrm{nmol} / \mathrm{L}$, there is an evolution towards the decrease of the circulating antibodies concentration determined on one handby treatment with plasmapheresis, and thymectomy on the other hand.

In both cases, the circulating antibody concentration witha steady decrease trend correlates with the improvement of the clinical picture for both patients.

It should also be taken into account that in both cases, the first two plasmapheresis sessions are performed 
preoperativelyto total resection of the thymus. Thus, on both graphics, there is a change in the dynamics ofthe decreasing tendency of the specific antibodies corresponding to the interval between plasmapheresis sitting 2 and sitting 3, when both patients underwent thymectomy.

Itcan also be noted that in both cases, the concentration of specific antibodies has a tendency to return to high values in the period immediately after surgery, followed by an eventual normalization of the values, with continued decreasing trend.

This can be explained by stress caused by surgery and is also reflected in the clinical picture of patients, with a tendency towards exacerbation, especially from a respiratory point of view.

In both cases, there is an increase in $\mathrm{SpO} 2$ in accordance with the time elapsed since the thymectomy. This is explained by taking into account the stress the patient underwent during surgery.

Both patients show oxygen saturation ranging between $70-80 \%$ on the first postoperative day. These values showed an evolution during the following days, such that on day 10 the values exceed $90 \%$, or close to normal.

In addition to these parameters, there is also a favourable evolution from a clinical perspective. Both patients exhibited a favourable medium-term progression, with some fluctuations especially in the early postoperative days.

Although they have a clear tendency towards a favourable medium to long-term progression after surgery, in both cases there was an exacerbation of the clinical picture immediately after surgery.

This tendency was more pronounced for the patient 1 , requiring mechanical ventilation for a longer period of time.

Oxygen saturation values may be correlated with decreased respiratory symptoms. In both cases, the symptoms specific to acute respiratory insufficiency tend to decrease in intensity. Patient 1 presented a faster positive evolution compared to patient 2 .

For both cases, we can observe the overcoming of the acute respiratory failure and the disappearance of the symptoms specific to the acute myastenic crisis, approximately 3 weeks after thymectomy.

Thus, we can note the positive results presented by patients in acute myasthenic crisis, following the combination of thymectomy with the plasmapheresis administered in the emergency setting.

During the first 2 weeks postoperatively, there was no significant progression in myasthenia gravis related symptoms.

The two patients received a postoperative 6-month assessment. Data was recorded about all procedures and parameters of interest during preoperative and first postoperative days.

Thus, the two patients received a CT scan, which certified the absence of long-term complications.

Also during the 6 month evaluation from surgery, the parameters initially recorded were measured. These are show $n$ in table 3.

In table 3, we can notice the long-term net positive evolution in both cases when comparing the data to the results upon admission.

When analyzing the concentration of specific antibodies, patient 2 has better outcomes than patient 1 . However, both patients experience a substantial decrease in antibody concentrations.

This evolution of specific antibodies may be correlated with thymus resection, butatleastduring the perioperative
Table 3

RESULTS OF THE 6 MONTHS OF SURGICAL INTERVENTION IN PATIENTSAMONG PATIENTS

\begin{tabular}{|l|l|l|}
\hline Parametru & Patient 1 & Patient 2 \\
\hline Ac AChr-ab & $12,5 \mathrm{nmol} / \mathrm{L}$ & $3 \mathrm{nmol} / \mathrm{L}$ \\
\hline $\mathrm{SpO}_{2}$ & $97 \%$ & $97 \%$ \\
\hline Palpebral ptosis & cured & Partialy cured \\
\hline Diplopia & - & Partialy cured \\
\hline Weakness of the limbs & cured & cured \\
\hline Weakness of axial muscles & cured & cured \\
\hline Signs of anemia & Absent & Absent \\
\hline
\end{tabular}

period, the decrease in antibodies was attributed to plasmapheresis.

In the postoperative period, it can be noticed that the surgery determined an increase in specific antibody concentrations in the short term, as a result of the stress on the body.

At the 6 months evaluation from surgery, the $\mathrm{SpO} 2$ values are normalized.

Normalization of oxygen saturation occurs at 6 months, under the conditions of complete clinical remission from the acute myasthenic crisis and from symptoms specific to associated acute respiratory failure.

From the point of view of specific affections associated with myasthenia gravis, the patient 1 shows a significantly better evolution, when compared to patient 2 , at 6 months post-op. ! In the case of the patient 1, there is a remission of palpebral ptosis, limb weakness, as well as the axial muscular weakness, in relation to the results of the evaluation during the first preoperative admission.

In case of patient 2, remission is found in signs of axial weakness and limb weakness. From the point of view of the respiratory manifestations found during the hospitalization prior to the timectomy. Partial remission of the diplopia and of palpebral ptosis is observed.

Both patients show resolution of anemia at 6 months after surgery.

All these results were obtained by association of longterm drug therapy, plasmapheresis immunotherapy and surgical intervention consisting of total thymus resection.

Taking into account the results obtained in the two cases, it can be concluded that overcoming of the acute myasthenic crisis episode is possible by receiving plasmapheresis while undergoing proper drug treatment.

This is done through prompt intervention in intensive care setting, followed by proper multidisciplinary management of the cases with myastenia gravis experiencing short-term exacerbations.

In addition to the specific examinations of myasthenia gravis and given that a pregnancy may be a trigger for an acute myasthenic crisis, both two female patients have been tested to eliminate the possibility of a pregnancy as cause of exacerbation.

In cases of acute myasthenic crisis with acute respiratory failure, prompt intervention with assisted mechanical ventilation is required whenever necessary.

Though thymectomy is the treatment that provides the most spectacular results in terms of specific antibodies concentration and clinical picture severity, in the conditions of an acute myastenic crisis, plasmapheresis leads to a rapid decrease of both aspects .

There were no noticeable effects in any of the evaluated cases in terms of limb or axial muscle weakness in the period immediately after surgery.

Effects on muscle weakness are generally seen in the 6 month post operative evaluation, by performing a myographic study on the patients. 


\section{Conclusions}

Plasmapheresis is the procedure that non selectively removes the potentially pathological elements from the blood. In patients with moderate or severe forms, or with no favourable therapeutic response to cholinesterase inhibitors, corticosteroids and / or immunosuppressive therapy are administered. Overcoming of the acute myasthenic crisis episode is possible by receiving plasmapheresis while undergoing proper drug treatment.

\section{References}

1.BUTCOVAN, D., OBOROCEANU, T., CIMPEANU, C., MIRONESCU, A., HALIGA, R.E., PINZARIU, A.C., LUPUSORU, R.V., POPESCU, E., MOCANU, V., Rev Chim. (Bucharest), 68, no. 4, 2017, p. 886-9;

2.HINGANU, D., STAN, C.I., TARANU, T., HINGANU, M.V. Rom J MorpholEmbryol, 58, no.4, 2017, p.1327;

3.CIUBOTARIU D, GHICIUC CM, LUPUSORU RV, BIBIRE N, AGOROAEI L, LUPUSORU CE. Farmacia 2015; 63(6):835-839;

4.MIHAI BM, PETRIS AO, UNGUREANU DA, LACATUSU CM. Open Medicine (former Cent Eur J Med) 2015; 10: 14-24;

5.HINGANU MV, STAN Cl, TARANU T, HINGANU D. Rom J Morphol Embryol 58, no.3, 2017, p. 851-855;
6.TOMA, A.G., SALAHORU P., HINGANU, M.V., HINGANU, D., DIMA COZMA, L. L., PATRASCU, A., GRIGORESCU C. Rev Chim (Bucharest), 70, no.1, 2019, p. 143;

7.HINGANU, M.V., SALAHORU, P., HINGANU, D. Rev Med Chir Soc Med Nat lasi, 122, no.3, 2018, p. 522;

8.LACATUSU C, CIJEVSCHI-PRELIPCEAN C, MIHAI C, MIHAI B. Rev Rom Bioet 2014; 12(1): 44-55;

9.GRIGORESCU, C., GAVRIL, L.C., GAVRIL, L., LUNGULEAC, T., CIUNTU, B.M., PATRASCU, A., SALAHORU, P., Rev. Chim. (Bucharest), 69, no. 9, 2018, p. 2591;

10.GAVRILESCU CM, FELEA MG, BARBU R, DUMA O, BODESCU MM, MIDILINA BODESCUL M, GHIURU R, BOERESCU C, PARASCHIV C. Rev. Med. Chir. Soc. Med.Nat.lasi 2016; 20(1): 48-53;

11.LUNGULEAC, T., HINGANU, M.V., GRIGORESCU, C., GAVRIL, L.C., SALAHORU, P., PATRASCU, A., HINGANU D., Rev. Chim. (Bucharest), 69, no. 10, 2018, p. 2937-2939;

12.IONIUC, I. DIACONU, LI. GRIGORESCU, C; ET AL. Procedia Technology, 22 (2016), pp. 413-418;

13.TRUFA DI, ARHIRE LI, GRIGORESCU C, MIHALACHE L, NITA O, GRAUR M, ET AL. Rev Romana Med Lab. 2015;23(1):75-86.

$\overline{\text { Manuscript received: } 17.08 .2018}$ 